\title{
Effect of nicotinamide on early graft failure following intraportal islet transplantation
}

\author{
Da-Yeon Jung ${ }^{1}$, Jae Berm Park'2, Sung-Yeon Joo', \\ Jae-Won Joh ${ }^{2}$, Choon-Hyuck Kwon ${ }^{2}$, \\ Ghee-Young Kwon ${ }^{3}$ and Sung-Joo Kim ${ }^{1,2,4}$ \\ ${ }^{1}$ Transplantation Research Center \\ Samsung Biomedical Research Institute \\ ${ }^{2}$ Department of Surgery \\ ${ }^{3}$ Department of Pathology \\ Samsung Medical Center \\ Sungkyunkwan University School of Medicine \\ Seoul 135-701, Korea \\ ${ }^{4}$ Corresponding author: Tel, 82-2-3410-3476; \\ Fax, 82-2-3410-0040; E-mail, kmhyj111@ hotmail.com \\ DOI 10.3858/emm.2009.41.11.084
}

Accepted 22 June 2009

Abbreviations: IBMIR, immediate blood mediated inflammatory reaction; IEQ, islet equivalent; IPGTT, intraperitoneal glucose tolerance test; IPIT, intraportal islet transplantation; MCP-1, monocyte chemoattractant protein-1; TF, tissue factor

\begin{abstract}
Intraportal islet transplantation (IPIT) may potentially cure Type 1 diabetes mellitus; however, graft failure in the early post-transplantation period presents a major obstacle. In this study, we tested the ability of nicotinamide to prevent early islet destruction in a syngeneic mouse model. Mice (C57BL/6) with chemically-induced diabetes received intraportal transplants of syngeneic islet tissue in various doses. Islets were cultured for $24 \mathrm{~h}$ in medium with or without $10 \mathrm{mM}$ nicotinamide supplementation. Following IPIT, islet function was confirmed by an intraperitoneal glucose tolerance test (IPGTT) and hepatectomy. The effects of nicotinamide were evaluated by blood glucose concentration, serum monocyte chemoattractant protein-1 (MCP-1) concentration, and immunohistology at $3 \mathrm{~h}$ and $24 \mathrm{~h}$ after IPIT. Among the various islet doses, an infusion of 300 syngeneic islets treated with nicotinamide exhibited the greatest differences in glucose tolerance between recipients of treated and untreated (i.e., control) islets. One day after 300 islet equivalent (IEQ) transplantation, islets treated with nicotinamide were better granulated than the un-
\end{abstract}

treated islets $(P=0.01)$, and the recipients displayed a slight decrease in serum MCP-1 concentration, as compared to controls. After 15 days, recipients of nicotinamide-pretreated islets showed higher levels of graft function (as measured by IPGTT) than controls. The pretreatment also prolonged graft survival ( $>100$ days) and function; these were confirmed by partial hepatectomy, which led to the recurrence of diabetes. Pretreatment of islet grafts with nicotinamide may prevent their deterioration on the early period following IPIT in a syngeneic mouse model.

Keywords: diabetes mellitus, type 1; hepatectomy; islets of Langerhans; islets of Langerhans transplantation; niacinamide

\section{Introduction}

Pancreatic islet transplantation is one of the most effective treatments for type 1 diabetes (Shapiro et al., 2000; Goss et al, 2002; Markmann et al., 2003). The general use of this treatment is limited, however, by the need for a large number of islet transplants (usually obtained from two organ donors) to achieve normoglycemia. In addition, the loss of functional islet mass $(50-70 \%)$ has been associated with stable islet engraftment (Contreras et al., 2004). To investigate the mechanisms of islet graft failure, many studies have used rodent models, most often with the kidney capsule as the transplantation site (Jung et al., 2006, 2008). Yet islets transplanted under the kidney capsule are protected from dynamic conditions in surrounding compartments, such as the post-gastrointestinal blood flow through the liver; and therefore data from studies that use this model may not apply directly to intraportal islet transplantation (IPIT) (Hara et al., 2004). Islets infused intraportally do not survive as well as transplants under the kidney capsule (Goto et al., 2004; Yin et al., 2006), which suggests that the intraportal infusions encounter more complex challenges.

Nicotinamide, a form of vitamin B3, participates in diverse biological processes through its major metabolite $\mathrm{NAD}^{+}$(nicotinamide adenine dinucleotide), including the production of energy, nutrient metabolism, signal transduction, and maintenance of genome integrity. As an inhibitor of poly 
(ADP-ribose) synthetase, nicotinamide may also prevent islet $\beta$-cell injury or destruction in nonobese diabetic (NOD) mice (Yamada et al., 1982) and mice with chemically-induced diabetes (Uchigata et al., 1983; Yamada et al., 1990). Importantly, this compound sustains islets in culture (Korsgren et al., 1993), increasing the resistance of $\beta$-cells to toxic chemicals, activated macrophages (Kolb et al., 1990), and inflammatory cytokines (Pipeleers and Van de Winkel 1986; Buscema et al., 1992; Kallmann et al., 1992). Based on these observations, nicotinamide has been tested for therapeutic effects in insulin-dependent diabetes of recent onset, in animal models and clinical trials (Elliott and Chase, 1991; Chase et al., 1992; Ueki et al., 1995). Especially, Ueki et al. (1995) reported that diabetic rats was injected I.P. with nicotinamide once a day for a 60 days after transplantation, finally, hyperglycemia can be ameliorated with an insufficient under of islet. Furthermore, isolated human or pig islet cells are also cultured in media with $10 \mathrm{mM}$ nicotinamide before transplantation to diabetic recipients
(Korsgren et al., 1993; Beattie et al., 2002; Ichii et al., 2006). These findings suggest that nicotinamide may be used to increase the efficiency and effectiveness of pancreatic islet transplantation.

In the present study, we applied islets cultured with nicotinamide, rather than daily I.P. injection with nicotinamide, to ameliorate hyperglycemia in diabetic mice following infusion into the hepatic portal vein. Using our syngeneic mouse model, we found that islets cultured with nicotinamide effectively prevented as well as decrease the number of islets required for successful transplantation. Moreover, islets cultured with nicotinamide delayed islet destruction and diabetes recurrence in the early post-transplantation phase.

\section{Results}

\section{Effect of islet transplantation by intraportal infusion}

To characterize the morphology of the implanted islets, we transplanted syngeneic islets (350 IEQ) to STZ-induced diabetic C57BL/6 mice by intra-
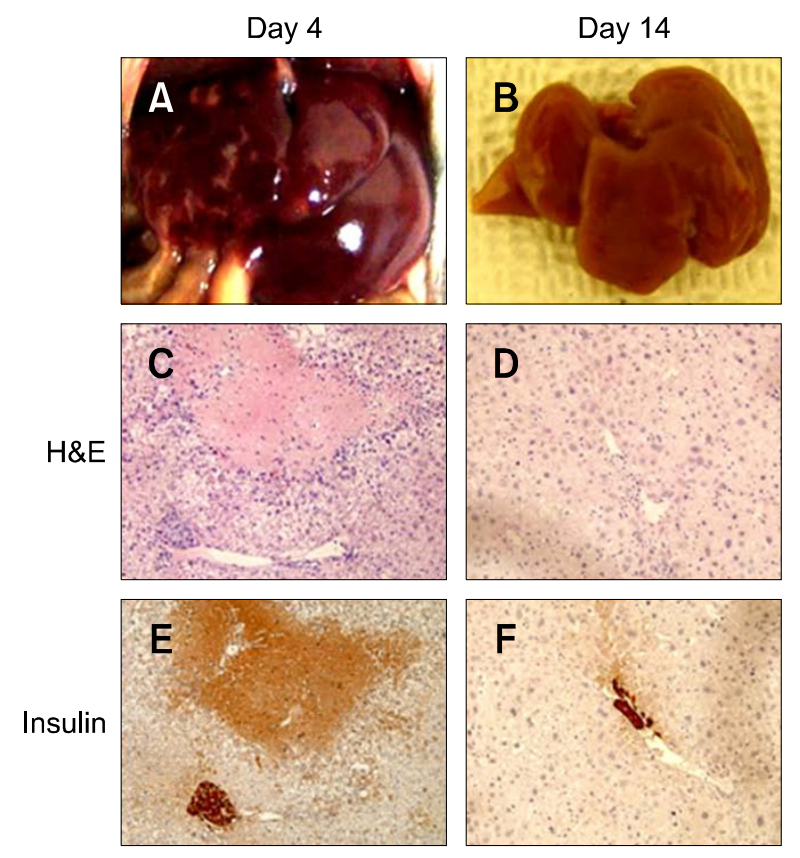
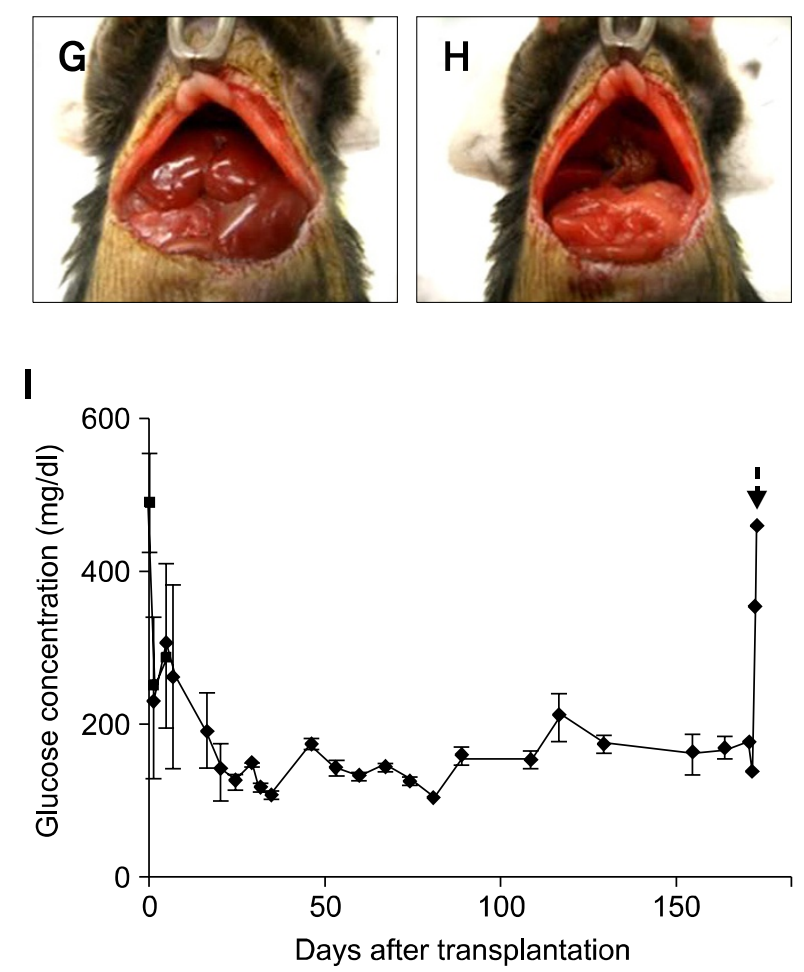

Figure 1. Evaluation of islet grafts early (days 4 and 12) and late (day 178) after intraportal islet transplantation. Four days (A, C, E) and 14 days (B, D, F) after islet transplantation, $70 \%$ of the liver was removed. Histological examination revealed multiple foci of necrosis on the liver surface (A, B). Hematoxylin/eosin staining (H\&E) (C, D), and immunoperoxidase staining with antibody against insulin (magnification $\times 200)(E, F)$ of liver sections, are shown. Histological sections for each marker are representative of three animals from each treatment group. In recipients of 350 islets with long-term graft survival, $70 \%$ of the liver was also removed $(\mathrm{G}, \mathrm{H})$. Blood glucose levels of recipients were monitored, and normoglycemic mice underwent partial hepatectomy at the time points indicated by arrows in (I) to confirm long-term graft function and acceptance. 
portal infusion. Four days after transplantation, we observed significant necrosis on the surface of the recipient liver, but it was resolved by day 14 (Figure $1 \mathrm{~A}$ and $1 \mathrm{~B}$ ). Islets were noted at day 4 post-transplantation, particularly within the areas of liver necrosis (Figure $1 \mathrm{C}$ and $1 \mathrm{E}$ ). In contrast, no necrosis was observed at day 14 post-transplantation (Figure 1D and 1F).

To confirm the engraftment site following IPIT, the liver was divided into five lobes and the average islet number per $\mathrm{cm}^{2}$ from each lobe was calculated. In the result, we observed that the transplanted islets were scattered over the five liver lobes (data not shown). To examine the function and acceptance of islets in long-term surviving grafts, three lobes of recipient livers (about $70 \%$, consisting of the middle lobes and left lobe) were removed on day 172 after the intraportal transplantation of 350 islets. These partially hepatectomized recipients subsequently displayed high glucose levels and developed recurrent diabetes (Figure 1G-I).

\section{Beneficial effect of nicotinamide treatment on islet grafts}

We examined the effect of nicotinamide on engraftment of different islet doses. Purified islets of C57BL/6 mice were cultured for $24 \mathrm{~h}$ in M199 medium with or without nicotinamide, and then
A

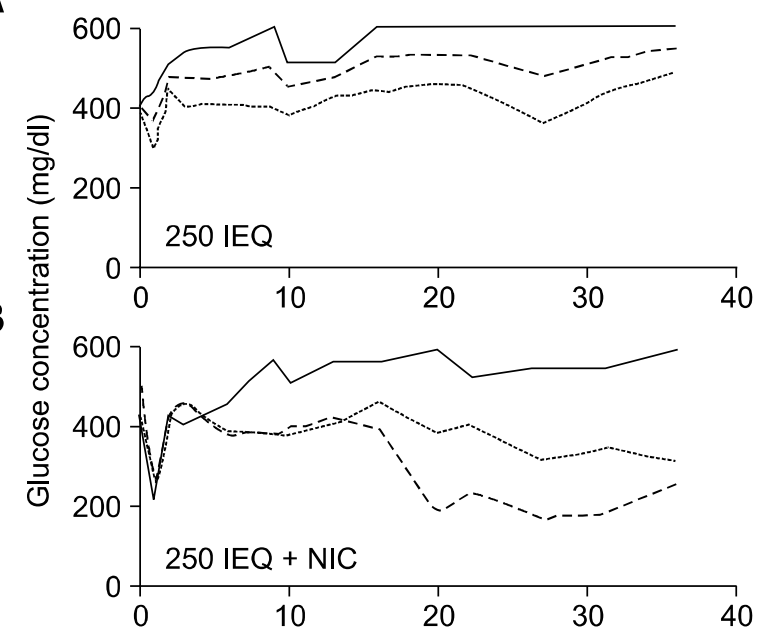

C

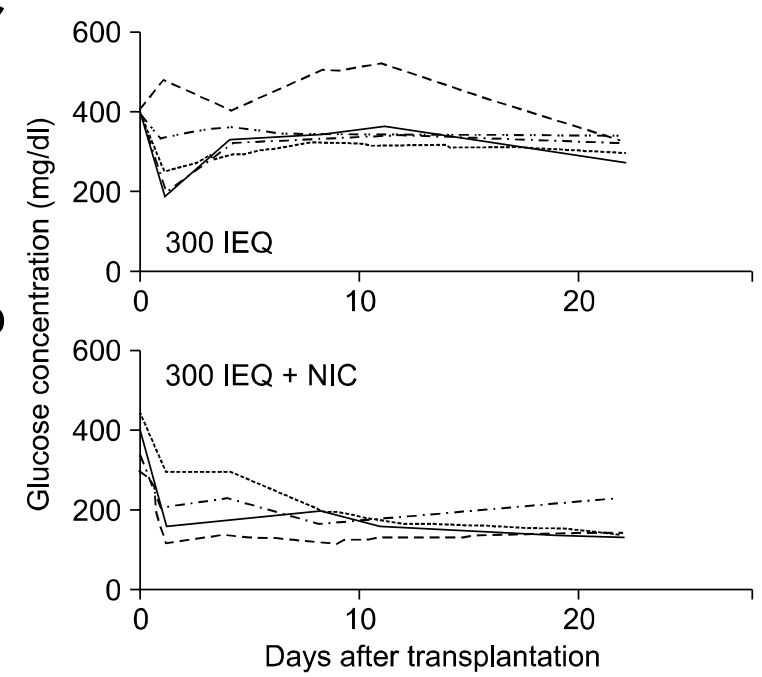

E

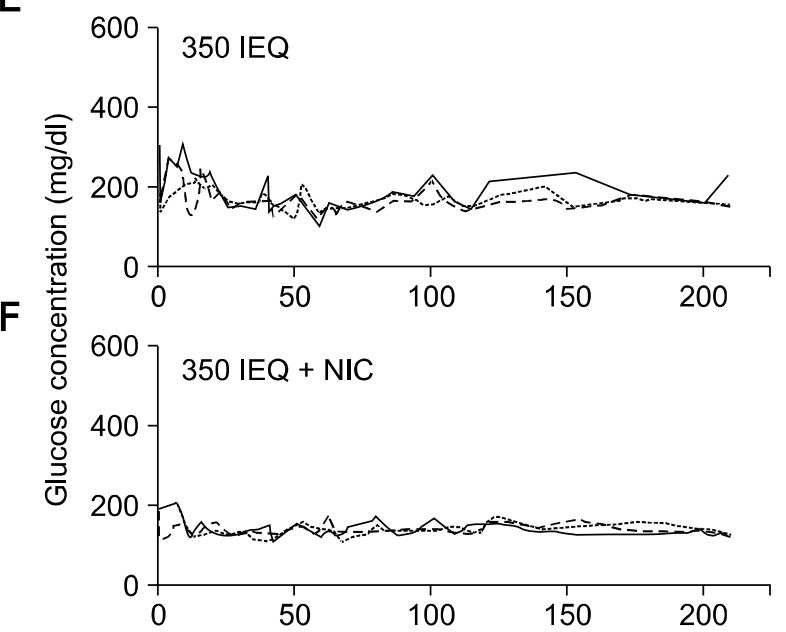

G

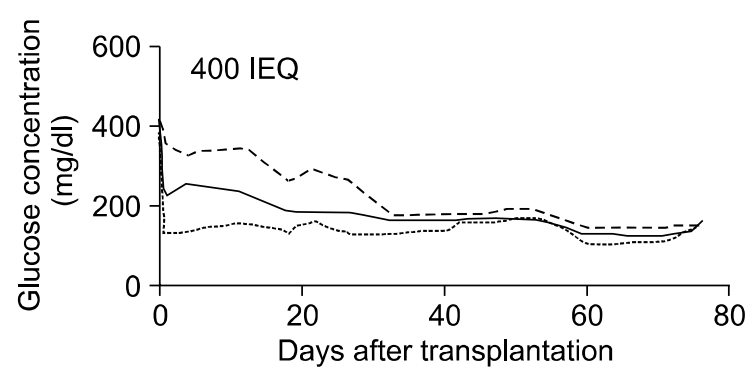

Figure 2. Beneficial effect of nicotinamide on the hyperglycemia in diabetic mice. Recipients received 250 (A, B), 300 (C, D), 350 ( $E, F)$, or 400 (G) syngeneic islets that were pretreated without $(A, C, E, G)$ or with $(B, D, F)$ nicotinamide. Individual lines represent the non-fasting plasma glucose levels of each animal. NIC, nicotinamide. 
transplanted to diabetic $\mathrm{C} 57 \mathrm{BL} / 6$ recipients in aliquots of $250,300,350$, or 400 islets, respectively. Diabetic recipients receiving 250 islets did not correct the diabetic hyperglycemia, although one of three mice with nicotinamide-treated islets became normoglycemic 20 days after transplantation (Figure $2 \mathrm{~A}$ and $2 \mathrm{~B}$ ). Mice that received 300 untreated islets maintained high glucose levels. In marked contrast to control mice, nicotinamide-treated islets (300 IEQ) suppressed the recipient's hyperglycemia on of the first day after transplantation (three of four recipients), and all were normalized after 10 days (Figure 2C and 2D). Mice that received 350 or 400 islets not pretreated with nicotinamide showed unstable glucose profiles (Figure 2E and 2G). In contrast, recipients of 350 nicotinamide-treated islets corrected their hyperglycemia and stabilized within one day of transplantation (Figure 2F).

\section{Enhanced glucose tolerance in recipients of nicotinamide-pretreated islet grafts}

To study the effect of nicotinamide-treated islet grafts on the whole-body glucose disposal rate, we

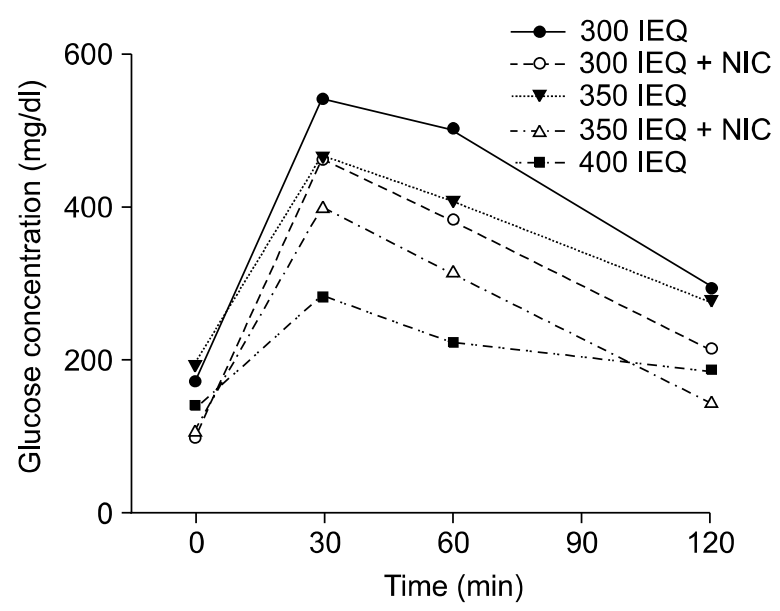

Figure 3. IPGTT in mice receiving islets with or without nicotinamide pretreatment. The IPGTT was performed in diabetic mice at 15 days post-transplantation. Experimental groups included diabetic mice that received 300,350 , or 400 syngeneic, nicotinamide-pretreated or untreated islets. The results for all five groups are expressed as mean plasma glucose concentrations $(n=3)$. NIC, nicotinamide.

performed IPGTTs on recipients of functioning grafts 15 days after transplantation. In recipients of
A

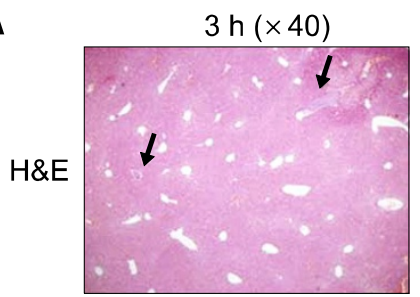

B

$24 \mathrm{~h}(\times 40)$

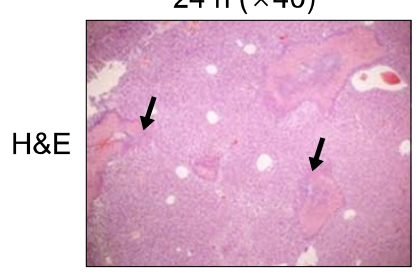

C

Insulin

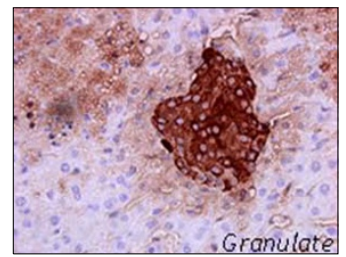

$3 \mathrm{~h}(\times 100)$

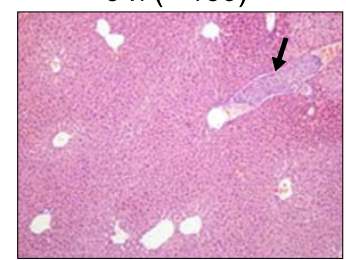

$24 \mathrm{~h}(\times 100)$
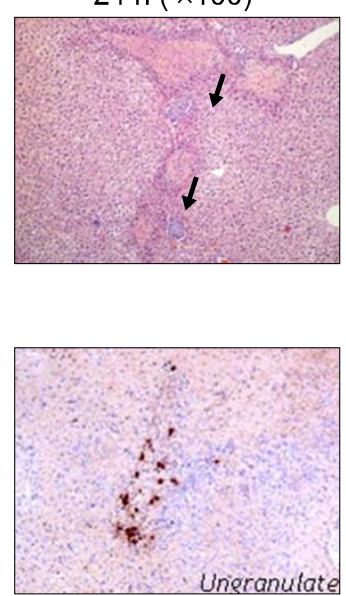

D

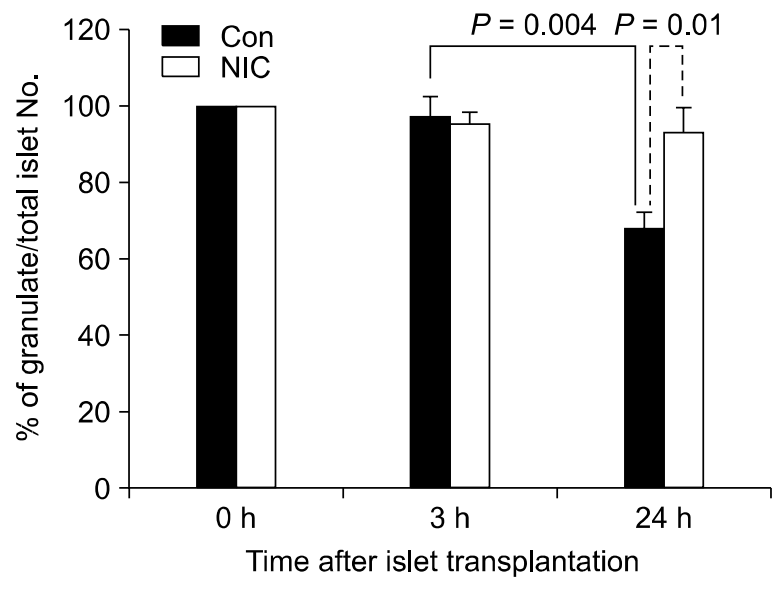

Figure 4. Morphological changes in the engrafted liver. Liver tissues were collected $3 \mathrm{~h}(\mathrm{~A})$ and $24 \mathrm{~h}$ post-transplantation $(\mathrm{B}, \mathrm{C})$, and stained with $\mathrm{H \& E}(\mathrm{A}$, $\mathrm{B}$ ) and monoclonal antibody to insulin (C). Insulin-positive cells were morphologically granulated or de-granulated (C, left or right, respectively). The percentage of granulation was based on the number of granulated islets out of the total number of insulin staining cells at 0,3 , and $24 \mathrm{~h}$ post-transplantation. The percentage of granulation at $0 \mathrm{~h}$ was calculated with islets before transplantation, and no de-granulated islets were observed. 
300 or 350 nicotinamide-treated islets, hyperglycemia induced by glucose injection (2 g/kg, i.p.) declined to the normal range within $2 \mathrm{~h}$ (Figure 3 ). Although recipients of 300 or 350 untreated islets continued to show blood glucose levels in the abnormal range for $2 \mathrm{~h}$, the amplitude of hyperglycemia and the kinetics of its decline did not differ significantly between groups that received 300 or 350 islets with or without treatment.

\section{Histological evaluation}

Following intraportal infusion with 300 untreated or nicotinamide-pretreated syngeneic islets, recipient livers were examined for pathology at $3 \mathrm{~h}$ and $24 \mathrm{~h}$ (Figure 4). The percentage of granulated islets was calculated by counting the total number of insulin-positive cells and then grouping them into granulated or de-granulated islets according to morphology (Figure 4C).

The morphology was similar in both groups at 3 $\mathrm{h}$ after IPIT (Figure 4A and 4D). Most insulin-positive cells were well-granulated, and these healthy islets were located in blood vessels. The condition of the liver was normal or slightly abnormal. After $24 \mathrm{~h}$, however, serious necrosis was observed in the islet recipients' livers. In the control group, more islets were de-granulated $(68 \%$ granulated) as compared with those after $3 \mathrm{~h}(96 \%$ granulated) $(P$ $=0.004$ ) (Figure 4B and 4D). In contrast, islets pretreated with nicotinamide were consistently well-granulated $(94 \%$ and $92 \%$ granulation at $3 \mathrm{~h}$ and $24 \mathrm{~h}$ after transplantation) and significantly different from untreated islets $(P=0.01)$ (Figure 4D).

\section{Expression of inflammatory mediators in the liver}

For RT-PCR and western blot, total RNA and protein were extracted from the recipient livers (lateral right and caudal lobe) at $3 \mathrm{~h}$ (Figure $5 \mathrm{~A}$ and $5 \mathrm{C}$ ) and $24 \mathrm{~h}$ (Figure 5B and 5D) after transplantation of 300 islets cultured with or without nicotinamide. At $3 \mathrm{~h}$ after IPIT, RNA expression of both TF and TNF- $\alpha$ had increased markedly in both groups; but by $24 \mathrm{~h}$, it had declined (Figure $5 \mathrm{~A}$ and $5 \mathrm{~B}$ ). IL-1 $\beta$ and MCP-1 were, however, weakly expressed in the liver after both $3 \mathrm{~h}$ and 24 $\mathrm{h}$ of IPTX. In addition, nicotinamide-pretreatment showed similar expression patterns to non-treatment. And also C3 was detected strongly in all recipient livers of both groups after $3 \mathrm{~h}$ in western blot (Figure 5C and 5D). Interestingly, C3 protein was found only a third in the nicotinamide pretreatment mice, whereas it was detected in all control recipients whole experimental period.

\section{Decreased serum MCP-1 concentration}

The concentration of serum MCP-1 was determined in recipients of untreated or nicotinamide-pretreated grafts on day one after intraportal infusion of 300 islets (Figure 6). Serum MCP-1 levels increased in all recipients after IPIT, but
A

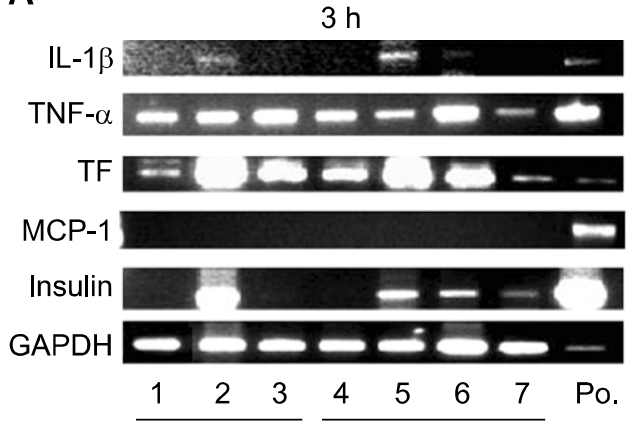

B
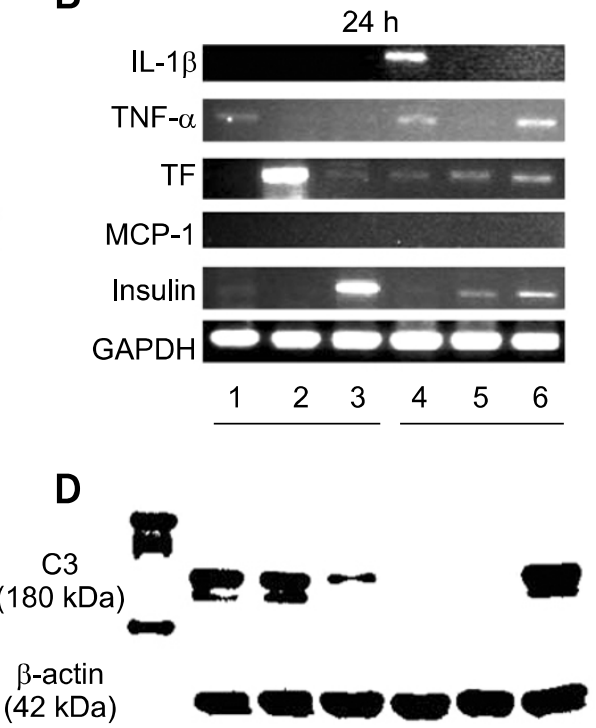

$\begin{array}{lll}M \quad \frac{1}{2} & 3\end{array} \frac{4}{\mathrm{CON}} \quad \frac{5}{\mathrm{NIC}}$
Figure 5. Expression of inflammatory mediators in the liver after IPTX. Islet cells pretreated without (control; lanes 1-3) or with nicotinamide (nicotinamide; lanes 4-6 and/or 7) were intraportally transplanted in the diabetic mouse. After $3 \mathrm{~h}$ or $24 \mathrm{~h}$ of transplantation, liver of recipient was sacrificed. RNA expressions for IL-1 $\beta$, TNF- $\alpha$, TF, MCP-1, insulin, and GAPDH were detected by RT-PCR analysis in the liver $3 \mathrm{~h}(\mathrm{~A})$ or $24 \mathrm{~h}$ (B) after IPTX. C3 and $\beta$-actin were detected by Western blot analysis in the liver sample at both times (C, D). Cell line RAW 264.7 activated by LPS was used as a positive control (Po.) of IL-1 $\beta$, TNF- $\alpha$, TF, MCP-1, and GAPDH. Cell line MIN 6 was used as a positive control of insulin. $\mathrm{NIC}$, nicotinamide. 


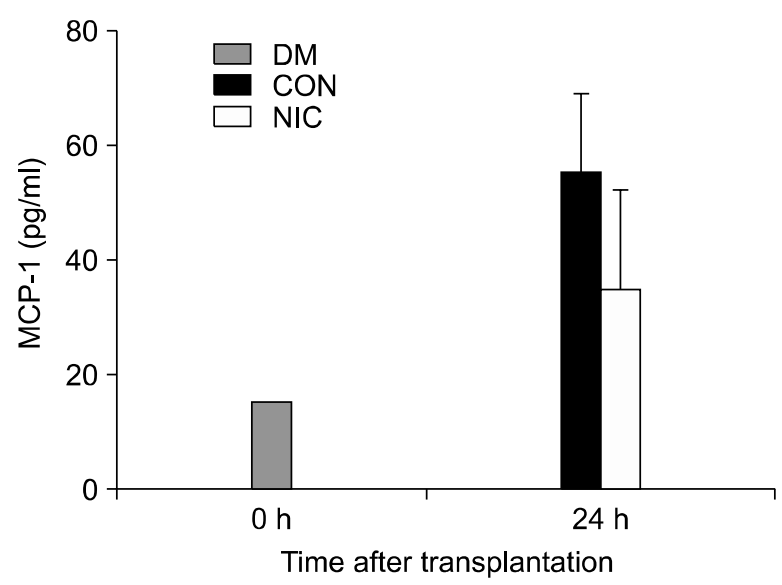

Figure 6. MCP-1 concentrations after intraportal transplantation of nicotinamide-pretreated and untreated islets. Diabetic mice receiving 300 IEQ with or without nicotinamide pretreatment were divided with two groups (CON, control; NIC, nicotinamide. pretreatment). At $24 \mathrm{~h}$ post-transplantation, MCP-1 concentrations were analyzed in recipient sera. Serum of diabetic mice (DM) was harvested before islet transplantation for the $0 \mathrm{~h}$ measurement.

were lower in the nicotinamide-pretreatment group (although the difference did not reach statistical significance).

\section{Effect of nicotinamide on long-term graft survival}

We examined the effect of nicotinamide on the diabetes cure rate and graft maintenance. Syngeneic islet cells (350 IEQ) with or without nicotinamide pretreatment were infused into the portal veins of diabetic mice. All mice receiving 350 nicotinamide-treated islets corrected their hyperglycemia on day one or by day nine $(67 \%$ or $33 \%$ of the recipients, respectively) following transplantation, and all $(100 \%)$ sustained their grafts for more than 200 days (Figure 7A). Recipients of untreated islet grafts were cured more gradually (33\% of recipients each on days 12,16 , and 23 ), and experienced more rapid recurrence of diabetes $(67 \%)$ than recipients of nicotinamide-treated islet grafts $(0 \%)$. Extended function of islets was confirmed by partial hepatectomy at 215 days post-transplantation. Islet cells in long-term surviving grafts were found around blood vessels, some infiltrated by immune cells (Figure 7B). Masson's trichrome stain revealed collagen-rich lesions of islet grafts in the liver (Figure 7C). Fibrosis in recipients with recurrent diabetes and hyperglycemia $(67 \%$ of control group) was observed in scattered islet clusters. In contrast, fibrotic tissue in surviving grafts of normoglycemic recipients $(33 \%$ of control group, and all of nicotinamide-treated group) were found around islets.

\section{Discussion}

The mechanism for the protective effect of nicotinamide pretreatment on islet tissue transplants is not well understood, although it may involve the scavenging of free radicals or the reduction of immunological injury to beta-cells (Buscema et al., 1992; Andersen et al., 1994). To explore this question, we examined the effect of the nicotinamide pretreatment on graft stability and function in a syngeneic mouse model of diabetes. With respect to glucose tolerance, mice that received nicotinamide-treated islets (300 IEQ) were superior to mice implanted with 300 or 350 untreated islets. The kinetics of glucose control also differed between the groups that received nicotinamide-treated and untreated islets. These observations suggest that this use of nicotinamide may reduce the number of donor islets required to control hyperglycemia in the diabetic recipient mice, at least in this syngeneic model. In addition, the nicotinamide pretreatment markedly reduced the deterioration of islets within the area of necrotic liver one day after islet infusion $(P=0.01)$. Serum MCP-1 expression following intraportal islet infusion was slightly lower in recipients of nicotinamide-treated islets, and the nicotinamide-pretreatment prolonged graft survival. From this we conclude that nicotinamide may reduce the adverse effects of intraportal infusion of syngeneic islets in C57BL/6 mice. In contrast to these results, however, we were unable to replicate the effects of nicotinamide on allogeneic islet transplantation: all transplant recipients remained hyperglycemic after infusion of 350 or 400 IEQ allogeneic islets (data not shown). We suggest that combined with an appropriate immunosuppressive regimen, nicotinamide may also prove beneficial in allogeneic islet transplantation via the portal vein.

In the porcine model, approximately $50 \%$ of islet cells are damaged in the first $20 \mathrm{~min}$ after the initiation of intraportal allotransplantation (Eich et al., 2007). In a syngeneic rat model of IPIT, an average of $43 \%$ of the infused tracer radioactivity was found in the liver $1 \mathrm{~h}$ after islet transplantation (Toso et al., 2005). Based on these and other observations, the authors suggested that inflammatory events immediately following IPIT (i.e. instant blood mediated inflammatory reaction, IBMIR) may have long-lasting effect on islet function.

Pretreatment of islets with nicotinamide may potentially suppress the synthesis of triggers for IBMIR, including tissue factor (TF), monocyte chemoattractant protein (MCP)-1, and other inflammatory cytokines (Moberg et al., 2003). The expre- 

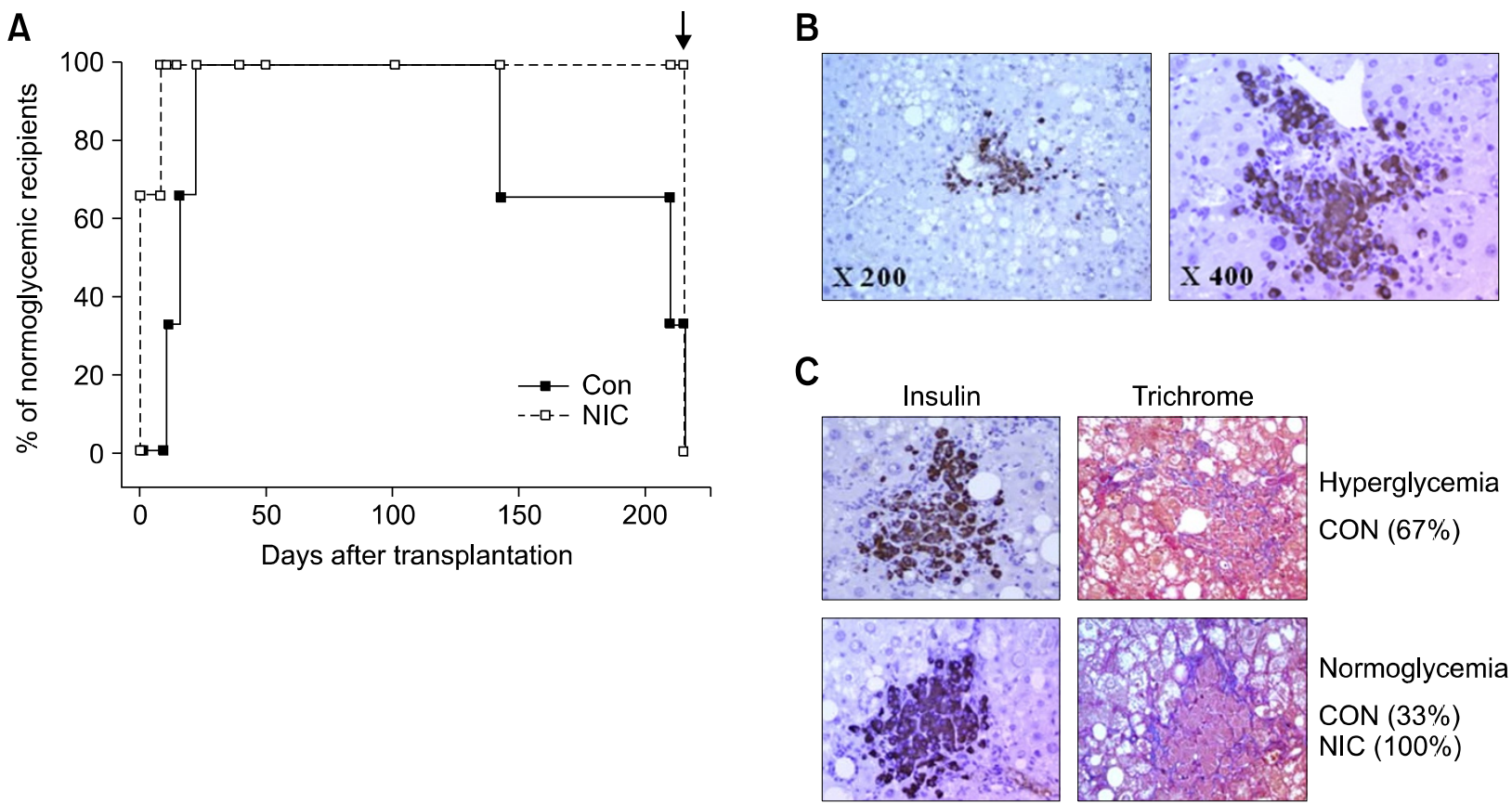

Figure 7. Diabetes cure rate and histology in long-term grafts. Diabetic mice that received 350 IEQ were divided into control (CON) (- - -) and NIC pretreatment (- $\square$-) groups. Long-term graft survival between groups was described as the percentage of recipients cured of diabetes (A). In order to confirm long-term graft function and acceptance, normoglycemic mice underwent partial hepatectomy of the graft-bearing liver at the time points indicated (arrows). Insulin positive-staining cells were observed near the blood vessels of long-term grafts (B). Islet cells were present in hyperglycemic (recurrent diabetes) and normoglycemic recipients (C: top and bottom panels, respectively). Beta cells were stained with anti-insulin antibody (dark brown color, left panel), and fibrotic lesions were detected by Masson's trichrome staining (blue color, right panel).

ssion of TF was strongly correlated with the level of MCP-1 $\left(r^{2}=0.98\right)$, and with the ability of islets to initiate IBMIR $\left(r^{2}=0.94\right)$, with thrombus formation. Moberg et al. (2005) also reported that levels of TF expression are strongly correlated with the relative potency of islets in initiating IBMIR in the in vitro loop model. Furthermore, the concentrations of TF and MCP-1 in islets show negative correlation with post-transplantation survival, i.e. low levels of these factors promote graft longevity (Piemonti et al., 2002; Berman et al., 2007).

Based on these observations, we evaluated islet loss at $3 \mathrm{~h}$ and $24 \mathrm{~h}$ after IPIT. At both time points, islets pretreated with nicotinamide were well granulated $(94.3 \pm 3.7 \%$ and $92.3 \pm 6.6 \%$, respectively) and significantly different from untreated islets $(96.6 \pm 5.9 \%$ and $68.2 \pm 3.9 \%$, respectively) $(P=0.01)$, suggesting that nicotinamide can prevent or delay islet destruction in the early period after IPIT. We also investigated whether nicotinamide was able to modulate inflammatory mediators such as TF, MCP-1, IL- $1 \beta$, TNF- $\alpha$, insulin and complement (C3) following IPIT in RT-PCR and western blot analysis. The expression of TF, TNF- $\alpha$, and $\mathrm{C} 3$ was increased markedly at $3 \mathrm{~h}$ after IPTX, while it was rapidly decreased at $24 \mathrm{~h}$ in both nicotinamide-pretreatment and non-treatment group.
These results would suggest that inflammatory mediators, such as TF, TNF- $\alpha$, and C3, were activated in the early phase (up to $3 \mathrm{~h}$ ) after islet transplantation. Interestingly, serum MCP-1 level of the nicotinamide-pretreatment group was lower than that of non-treatment group on day one after IPTX (not statistically significant), whereas RNA of MCP-1 was weakly expressed in the recipient livers of both groups after $3 \mathrm{~h}$ and $24 \mathrm{~h}$ of transplantation. In our result, the correlation of between serum MCP-1 concentration and RNA expression of MCP-1 was not significant. Thus, presumably, to understand the role of nicotinamide pretreatment, the quantitative studies including Real-time PCR during early phase (up to $3 \mathrm{~h}$ ) would be needed.

Nicotinamide suppresses TF expression in several islet transplantation models (Moberg et al., 2002, 2003, 2005; Berman et al., 2007). After activation by an extrinsic pathway, TF induces thrombin formation (Moberg 2005) then thrombin converts fibrinogen to insoluble fibrin (Ozmen et al., 2002; Andrades et al., 2007) and activates the complement system, especially C3 and C5 (Andrades et al., 2007). We speculate that nicotinamide pretreatment may alter expression of these mediators very early $(<3 \mathrm{~h})$ after IPIT. We also suggest that the reduction in TF expression and 
thrombin formation following nicotinamide treatment suppresses early C3 activation. Moreover, the reduction of these factors may prolong graft survival and reduce the formation of insoluble fibrin in hyperglycemic recipients, as shown in our study, although the mechanism for the anti-inflammatory action of nicotinamide on TF was not well known.

This action, however, may be highly relevant, not only to the pro-coagulative activity of islets, but also the inflammatory response, in both the early recruitment of immune cells and the activation of specific immunity (Chase et al., 1992) that occurs after transplantation (Yamada et al., 1990; Buscema et al., 1992; Andersen et al., 1994). nicotinamide promotes islet regeneration (Yonemura et al., 1984), induces differentiation (Hellerstrom 1984; Sandler and Andersson 1988), and enhances insulin biosynthesis (Ye et al., 2006). Based on these properties, we suggest that nicotinamide may serve several therapeutic roles in the early post-transplantation period, to prevent IBMIR and promote graft survival after intraportal islet infusion.

We conclude that nicotinamide-pretreated islets suppressed hyperglycemia more efficiently than control islets in a syngeneic mouse model of IPIT. Three hours after transplantation, the pre-treatment group did not differ morphologically from controls; but after $24 \mathrm{~h}$, the degranulated islets in necrotic areas of the liver were markedly reduced in the pretreated grafts. Nicotinamide treatment also prolonged graft survival and reduced the frequency of fibrotic lesions. We propose that nicotinamide pretreatment may function to prevent the deterioration of islet grafts following IPIT in diabetic patients. Further studies are required to completely understand the effects of nicotinamide on IBMIR in intrahepatic islet transplantation. Additional agents will be needed to fully control inflammation and reduce the number of islets required to achieve insulin independence.

\section{Methods}

\section{Animals and induction of diabetes}

Adult male 12-week-old C57BL/6 (H-2d) mice (Jackson Laboratories, Bar Harbor, ME) served as donors and recipients for IPIT. All animals were housed in accordance with the Samsung Biomedical Research Institute's Principles of Laboratory Animal Care and Guide for the Use of Laboratory Animals. To induce diabetes, mice were given serial intraperitoneal injections of streptozotocin (STZ, 180 $\mathrm{mg} / \mathrm{kg}$, Sigma Chemical Co., St. Louis, MO). Blood glucose concentrations were measured in whole blood samples collected from the tail veins of the injected mice with Accu-Chek Advantage Glucose Monitors (Roche Diagnostics, Indianapolis, IN). Diabetic mice that had non-fasting blood glucose values higher than $400 \mathrm{mg} / \mathrm{dl}$ for more than two consecutive days were used as recipients of islet grafts.

\section{Islet isolation and transplantation}

Islets were isolated from the C57BL/6 mouse pancreas by digestion with collagenase $\mathrm{P}(0.8 \mathrm{mg} / \mathrm{ml}$; Roche Diagnostics $)$ followed by purification in a Ficoll gradient (Sigma-Aldrich) (Gotoh et al., 1986). Islets were then cultured overnight at $37^{\circ} \mathrm{C}$, with $5 \% \mathrm{CO}_{2}$, in $\mathrm{M} 199$ medium (Gibco, Long Island, NY) supplemented with 10\% FBS (Hyclone, Logan, UT), 2 $\mathrm{mM}$ L-glutamine, 100 units $/ \mathrm{ml}$ penicillin, and $100 \mu \mathrm{g} / \mathrm{ml}$ streptomycin. Purified islets were cultured for $24 \mathrm{~h}$ in this medium, with or without $10 \mathrm{mM}$ nicotinamide (Sigma-Aldrich, St. Louis, MO), and transplanted into the liver via the portal vein with an injector. This injector, modified and developed in our laboratory, was constructed from a 27-gauge needle, 20-gauge catheter, and $1 \mathrm{cc}$ syringe. Blood glucose concentrations in the recipient mice were monitored biweekly after transplantation. Non-fasting blood glucose concentrations greater than $300 \mathrm{mg} / \mathrm{dl}$ for two consecutive measurements in a single week were accepted as evidence of graft failure.

\section{Partial hepatectomy}

To confirm the success of IPIT in our mouse model, we tested the ability of partial hepatectomy to cause recurrence of diabetes in the longest-surviving mice. We used partial hepatectomy in our IPIT model, in analogy to the diabetogenic effect of partial pancreatectomy in normal mice (Morales et al., 2005). The liver has five lobes (lateral left, medial left, medial right, lateral right, and caudal lobe), and $70 \%$ partial hepatectomy is routinely performed in animal research (Greene and Puder, 2003). We removed the median and left lateral lobes in the surviving mice, then monitored blood glucose concentration to assess the activity of the islet graft in the control of diabetes.

\section{Intraperitoneal glucose tolerance test}

We performed an intraperitoneal glucose tolerance test (IPGTT) in the graft recipients 15 days after IPIT. Briefly, after overnight fasting, unanesthetized mice were injected IP with a $50 \%$ glucose solution $(2 \mathrm{~g} / \mathrm{kg}$ body $\mathrm{wt})$. Plasma glucose concentrations were measured at $0,30,60$, and 120 min thereafter.

\section{Histological analysis}

To characterize islet graft morphology, we took liver samples from recipient mice at 3 and $24 \mathrm{~h}$ following IPIT, and on day 215 , we also performed $70 \%$ partial hepatectomies. Between three and five recipients were examined in each experiment. The entire or partial liver was divided into individual lobes, fixed in $10 \%$ formalin, and prepared for histological analysis. We prepared $6 \mu \mathrm{m}$ step-sections at $200 \mu \mathrm{m}$ intervals, and calculated the total number of islets and the area of each of the three step-sections in each lobe. The islet number in the liver was defined as the 
average islet number per $\mathrm{cm}^{2}$ from all five lobes. Functional islets were identified using anti-insulin polyclonal antibody (Dako, Carpinteria, CA) to assess insulin expression of islet beta cells. Masson's trichrome staining kit (Sigma) was used to identify collagen-rich fibrotic lesions in the liver. A pathologist, who was blind to the treatment status of the transplanted graft donors, evaluated all islet graft specimens for the presence of inflammatory cells, insulin, glucagons, and apoptotic cells. Controls included the omission of primary antibodies and the use of species-matched nonbinding control antibodies.

\section{RT-PCR}

Liver samples were obtained at $3 \mathrm{~h}$ and $24 \mathrm{~h}$ following transplantation of islets treated with or without nicotinamide and were subject to total RNA extraction using Trizol reagent (Invitrogen). After RNA quantification, $1 \mu \mathrm{g}$ of total RNA was treated with RNase-free DNase I (Roche), followed by reverse transcription using Omniscript RT Kit (Qiagen) as described by the manufacturer's instructions. GAPDH mRNA was amplified simultaneously as a control. The following primers were used: IL- $1 \beta$ forward (5'-CCGTGGACCTTCCAGGATGA-3') and reverse (5'-GATCCACACTCTCCAGCTGC-3'); TNF- $\alpha$ forward (5'-GGCAGGTCTACTTTGGAGTCATTGC-3') and reverse (5'- CATTCGAGGCTCCAGTGAATTCGG-3'); TF forward (5'-CGGGTGCAGGCATTCCAGAG-3') and reverse (5'-CTCCGTGGGACAGAGAGGAC-3'); MCP-1 forward (5'-TCTCTTCCTCCACCACCATGCAG-3') and reverse (5'-GGAAAAATGGATCCACACCTTGC-3'); insulin forward (5'-TCCTACCCCTGCTGGCCCTGC-3') and reverse (5'-AGTTGCAGTAGTTCTCCAG-3'); and GAPDH forward (5'-ACCACAGTCCATGCCATCAC-3') and reverse (5'-TCCACCACCCTGTTGCTGTA-3'). Conditions for the reaction are as follows: initial denaturation at $94^{\circ} \mathrm{C}$ for $5 \mathrm{~min}$, followed by 35 cycles of $94^{\circ} \mathrm{C}$ denaturation $(45 \mathrm{~s}), 59^{\circ} \mathrm{C}$ annealing ( $1 \mathrm{~min}$; IL-1 $\beta, \mathrm{TF}$, and $\mathrm{MCP}-1)$, and $72^{\circ} \mathrm{C}$ extension $(1 \mathrm{~min})$, with a final extension at $72^{\circ} \mathrm{C}$ for $5 \mathrm{~min}$. Annealing temperature and time of insulin, TNF- $\alpha$, and GAPDH is $30 \mathrm{~s}$ at $56^{\circ} \mathrm{C}, 1 \mathrm{~min}$ at $60^{\circ} \mathrm{C}$, and $30 \mathrm{~s}$ at $60^{\circ} \mathrm{C}$, respectively. RT-PCR products were analyzed by electrophoresis on a $1.5 \%$ agarose gel. The murine monocyte/macrophage cell line RAW 264.7 was obtained from the Korean Cell Line Bank (Seoul, Korea), and used as a positive control of inflammatory mediators. To induce expression of inflammatory mediators, cells were activated with $10 \mathrm{ng} / \mathrm{ml}$ LPS (Sigma Chemical Co., St. Louis, MO) for $6 \mathrm{~h}$, and then harvested for RNA isolation. Cell line MIN 6 was used as a positive control of insulin.

\section{Western blot analysis}

Liver samples were obtained at $3 \mathrm{~h}$ and $24 \mathrm{~h}$ following IPTX and were homogenized in PBS/Protease Inhibitor cocktail and RIPA lysis buffer. Cellular protein from each sample (50 $\mu \mathrm{g})$ was mixed with sample buffer $(0.25 \mathrm{M}$ Tris, $\mathrm{pH} 6.8,8 \%$ SDS, $40 \%$ glycerol, $2.5 \%$ bromphenol blue, and $2 \%$ $\beta$-mercaptoethanol) and subjected to $10 \%$ SDS-PAGE, and then blotted on nitrocellulose (Amersham Pharmacia Biotech, Piscataway, NJ). The membranes were blocked overnight with $5 \%$ non-fat milk in Tris-buffered saline containing $0.1 \%$ Tween 20 (TBST) at $4^{\circ} \mathrm{C}$ and then incubated with monoclonal anti-mouse C3 (1:200; Santa Cruz, Biotechnology, CA) or polyclonal rabbit anti- $\beta$-actin (1:1000; Abcam, Cambridge, UK) in 5\% non-fat milk in PBS containing $0.1 \%$ Tween 20 (PBT) for $4 \mathrm{~h}$ at RT. After the blot was washed with TBST, it was incubated for $1 \mathrm{~h}$ at RT with secondary HRP-conjugated anti-mouse IgG (1:1000; eBioscience) or anti-rabbit IgG (1:2000; Biolegend). Immunoreactive bands were revealed using an ECL-plus kit. Blots were visualized using the chemiluminescence detection system (Amersham Pharmaceuticals, Amersham, UK).

\section{Serum MCP-1 content}

The plasma concentration of MCP-1 was quantified using a commercially available ELISA kit (Quantikine MCP-1; R\&D Systems Europe Ltd., Abingdon, United Kingdom). Blood samples were obtained one day after islet transplantation. Plasma was separated, frozen immediately, and stored at $-70^{\circ} \mathrm{C}$ until use.

\section{Data analysis}

All values reported represent the mean \pm standard deviation. Statistical analysis of survival and granulation among the treatment groups was performed using the Statistical Package for Social Sciences (SPSS for Windows 15.0; SPSS Inc, Chicago, IL) with the Log Rank test. $P$ values $<0.05$ were considered to be statistically significant.

\section{Acknowledgments}

This research was supported by grants from the IN-SUNG Foundation for Medical Research.

\section{References}

Andersen HU, Jorgensen KH, Egeberg J, Mandrup-Poulsen T, Nerup J. Nicotinamide prevents interleukin-1 effects on accumulated insulin release and nitric oxide production in rat islets of Langerhans. Diabetes 1994;43:770-7

Andrades P, Asiedu C, Rodriguez C, Goodwin J, Deckard LA, Jargal U, Balgansuren G, Thomas JM. Insulin secretion from pancreatic islets in fibrin glue clots at different fibrinogen and thrombin concentrations. Transplant Proc 2007;39:1607- 8

Beattie GM, Montgomery AM, Lopez AD, Hao E, Perez B, Just ML, Lakey JR, ME Hart and A. Hayek. A novel approach to increase human islet cell mass while preserving $\beta$-cell function. Diabetes 2002;51:3435-9

Berman DM, Cabrera O, Kenyon NM, Miller J, Tam SH, Khandekar VS, Picha KM, Soderman AR, Jordan RE, Bugelski PJ, Horninger D, Lark M, Davis JE, Alejandro R, Berggren PO, Zimmerman M, O'Neil JJ, Ricordi C, Kenyon NS. Interference with tissue factor prolongs intrahepatic islet allograft survival in a nonhuman primate marginal mass model. Transplantation 2007;84:308-15

Buscema M, Vinci C, Gatta C, Rabuazzo MA, Vignen R, Purrello F. Nicotinamide partially reverses the interleukin-1 
beta inhibition of glucose-induced insulin release in pancreatic islets. Metabolism 1992;41:296-300

Chase P, Dupre J, Mahon J, Ehrlich R, Gale E, Kolb H, Lampeter E, Nerup J. Nicotinamide and prevention of diabetes. Lancet 1992;339:1051-2

Contreras JL, Eckstein C, Smyth CA, Bilbao G, Vilatoba M, Ringland SE, Young C, Thompson JA, Fernandez JA, Griffin $\mathrm{JH}$, Eckhoff DE. Activated protein $\mathrm{C}$ preserves functional islet mass after intraportal transplantation: a novel link between endothelial cell activation, thrombosis, inflammation, and islet cell death. Diabetes 2004; 53:2804-14

Eich T, Eriksson O, Sundin A, Estrada S, Brandhorst D, Brandhorst $\mathrm{H}$, Langstrom $\mathrm{B}$, Nilsson $\mathrm{B}$, Korsgren $\mathrm{O}$, Lundgren T. Positron emission tomography: a real-time tool to quantify early islet engraftment in a preclinical large animal model. Transplantation 2007;84:893-8

Elliott RB, Chase HP. Prevention or delay of type 1 (insulindependent) diabetes mellitus in children using nicotinamide. Diabetologia 1991;34:362-5

Goss JA, Schock AP, Brunicardi FC, Goodpastor SE, Garber AJ, Soltes G, Barth M, Froud T, Alejandro R, Ricordi C. Achievement of insulin independence in three consecutive type-1 diabetic patients via pancreatic islet transplantation using islets isolated at a remote islet isolation center. Transplantation 2002;74:1761-6

Goto M, Johansson H, Maeda A, Elgue G, Korsgren O, Nilsson B. Low molecular weight dextran sulfate prevents the instant blood-mediated inflammatory reaction induced by adult porcine islets. Transplantation 2004;77:741-7

Gotoh M, Maki T, Satomi S, Porter J, Monaco AP. Immunological characteristics of purified pancreatic islet grafts. Transplantation 1986;42:387-90

Greene AK, Puder M. Partial hepatectomy in the mouse: technique and perioperative management. J Invest Surg 2003;16:99-102

Hara M, Yin D, Dizon RF, Shen J, Chong AS, Bindokas VP. A mouse model for studying intrahepatic islet transplantation. Transplantation 2004;78:615-8

Hellerstrom C. The life story of the pancreatic B cell. Diabetologia 1984;26:393-400

Ichii H, Wang X, Messinger S, Alvarez A, Fraker C, Khan A, Kuroda Y, Inverardi L, Goss JA, Alejandro R, Ricordi C Improved human islet isolation using nicotinamide. Am $\mathrm{J}$ Transplant 2006;6:2060-8

Jung DY, Lee HJ, Lee EN, Lee J, Kim EY, Park HJ, Chang CY, Lee SK, Joh JW, Kwon GY, Kim SJ. Beneficial effects of simultaneous treatment with 15-deoxyspergualin and monoclonal antibodies to CD45RB and CD154 on murine islet transplantation recipients. Transplantation 2006;82: 188-95

Jung DY, Kim EY, Joo SY, Park JB, Moon C, Kim SH, Sim EY, Joh JW, Kwon CH, Kwon GY, Kim SJ. Prolonged survival of islet allografts in mice treated with rosmarinic acid and anti-CD154 antibody. Exp Mol Med 2008;40:1-10

Kallmann B, Burkart V, Kroncke KD, Kolb-Bachofen V, Kolb $\mathrm{H}$. Toxicity of chemically generated nitric oxide towards pancreatic islet cells can be prevented by nicotinamide. Life Sci 1992;51:671-8

Kolb H, Burkart V, Appels B, Hanenberg H, Kantwerk-Funke G, Kiesel U, Funda J, Schraermeyer U, Kolb-Bachofen V. Essential contribution of macrophages to islet cell destruction in vivo and in vitro. J Autoimmun 1990;3 Suppl 1:117-20

Korsgren O, Andersson A, Sandler S. Pretreatment of fetal porcine pancreas in culture with nicotinamide accelerates reversal of diabetes after transplantation to nude mice. Surgery 1993;113:205-14

Markmann JF, Deng S, Huang X, Desai NM, Velidedeoglu EH, Lui C, Frank A, Markmann E, Palanjian M, Brayman K, Wolf B, Bell E, Vitamaniuk M, Doliba N, Matschinsky F, Barker CF, Naji A. Insulin independence following isolated islet transplantation and single islet infusions. Ann Surg 2003; 237:741-9; discussion 749-50

Moberg L. The role of the innate immunity in islet transplantation. Ups J Med Sci 2005;110:17-55

Moberg L, Johansson H, Lukinius A, Berne C, Foss A, Kallen R, Ostraat O, Salmela K, Tibell A, Tufveson G, Elgue G, Nilsson Ekdahl K, Korsgren O, Nilsson B. Production of tissue factor by pancreatic islet cells as a trigger of detrimental thrombotic reactions in clinical islet transplantation. Lancet 2002;360:2039-45

Moberg L, Olsson A, Berne C, Felldin M, Foss A, Kallen R, Salmela K, Tibell A, Tufveson G, Nilsson B, Korsgren O. Nicotinamide inhibits tissue factor expression in isolated human pancreatic islets: implications for clinical islet transplantation. Transplantation 2003;76:1285-8

Morales AP, Conde EG, Lopez MG, Valle MI, Diaz JF, Jauregui $\mathrm{PH}$. An improved method of $90 \%$ pancreatectomy using a low dose of streptozotocin at the pancreaticoduodenal artery results in a rapid diabetic stage in dogs. Acta Diabetol 2005;42:153-5

Ozmen L, Ekdahl KN, Elgue G, Larsson R, Korsgren O, Nilsson B. Inhibition of thrombin abrogates the instant blood-mediated inflammatory reaction triggered by isolated human islets: possible application of the thrombin inhibitor melagatran in clinical islet transplantation. Diabetes 2002; $51: 1779-84$

Piemonti L, Leone BE, Nano R, Saccani A, Monti P, Maffi P, Bianchi G, Sica A, Peri G, Melzi R, Aldrighetti L, Secchi A, Di Carlo V, Allavena P, Bertuzzi F. 2002. "Human pancreatic islets produce and secrete MCP-1/CCL2: relevance in human islet transplantation." Diabetes 2002;51:55-65

Pipeleers D, Van de Winkel M. Pancreatic B cells possess defense mechanisms against cell-specific toxicity. Proc Natl Acad Sci USA 1986;83:5267-71

Sandler S, Andersson A. Stimulation of cell replication in transplanted pancreatic islets by nicotinamide treatment. Transplantation 1988:46:30-1

Shapiro AM, Lakey JR, Ryan EA, Korbutt GS, Toth E, Warnock GL, Kneteman NM, Rajotte RV. Islet transplantation in seven patients with type 1 diabetes mellitus using a glucocorticoid-free immunosuppressive regimen. $\mathrm{N}$ Engl J Med 2000;343:230-8 
Toso C, Zaidi H, Morel P, Armanet M, Andres A, Pernin N, Baertschiger R, Slosman D, Buhler LH, Bosco D, Berney T. Positron-emission tomography imaging of early events after transplantation of islets of Langerhans. Transplantation 2005;79:353-5

Uchigata $\mathrm{Y}$, Yamamoto $\mathrm{H}$, Nagai $\mathrm{H}$, Okamoto H. Effect of poly(ADP-ribose) synthetase inhibitor administration to rats before and after injection of alloxan and streptozotocin on islet proinsulin synthesis. Diabetes 1983;32:316-8

Ueki M, Yasunami Y, Motoyama K, Funakoshi A, Ikeda, S, Tanaka M. The amelioration of hyperglycemia in streptozotocin-induced diabetic rats after the intraportal transplantation of an insufficient number of islets by nicotinamide treatment. Transplantation 1995;60:313-7

Yamada K, Miyajima E, Nonaka K. Inhibition of cytokineinduced MHC class II but not class I molecule expression on mouse islet cells by niacinamide and 3-aminobenzamide. Diabetes 1990;39:1125-30
Yamada K, Nonaka K, Hanafusa T, Miyazaki A, Toyoshima $H$, Tarui S. Preventive and therapeutic effects of large-dose nicotinamide injections on diabetes associated with insulitis. An observation in nonobese diabetic (NOD) mice. Diabetes 1982;31:749-53

Ye DZ, Tai MH, Linning KD, Szabo C, Olson LK. MafA expression and insulin promoter activity are induced by nicotinamide and related compounds in INS-1 pancreatic $\beta$-cells. Diabetes 2006;55:742-50

Yin D, Ding JW, Shen J, Ma L, Hara M, Chong AS. Liver ischemia contributes to early islet failure following intraportal transplantation: benefits of liver ischemic-preconditioning. Am J Transplant 2006;6:60-8

Yonemura Y, Takashima T, Miwa K, Miyazaki I, Yamamoto H, Okamoto $\mathrm{H}$. Amelioration of diabetes mellitus in partially depancreatized rats by poly(ADP-ribose) synthetase inhibitors. Evidence of islet B-cell regeneration. Diabetes 1984;33:401-4 